\title{
PROCESSOS EDUCATIVOS E MOVIMENTOS SOCIAIS POPULARES DO CAMPO NO OESTE CATARINENSE
}

\author{
EDUCATIVE PROCESSOS AND POPULAR SOCIAL MOVEMENTS OF THE \\ COUNTRYSIDE IN WESTERN SANTA CATARINA
PROCESOS EDUCATIVOS Y MOVIMIENTOS SOCIALES POPULARES DEL CAMPO EN OESTE CATARINENSE

Odilon Luiz Poli*

odilon@unochapeco.edu.br

Rosana Maria Badalotti**

rosana@unochapeco.edu.br

Sirlei Antoninha Kroth Gaspareto***

sirlei@unochapeco.edu.br

\begin{abstract}
REVISTA PEDAGÓGICA
Revista do Programa de Pós-graduação em Educação da Unochapecó | ISSN 1984-1566

Universidade Comunitária da Região de Chapecó | Chapecó-SC, Brasil

Como referenciar este artigo: POLI, O. L.; BADALOTTI, R. M.; GASPARETO, S. A. K. Processos

educativos e movimentos sociais populares do campo no oeste catarinense. Revista Pedagógica,

Chapecó, v. 19, n. 40, p. 196-215, jan./abr. 2017. DOI: http://dx.doi.org/10.22196/rp.v19i40.3750
\end{abstract}

\begin{abstract}
RESUMO: Os movimentos sociais populares do campo que surgiram no Oeste Catarinense, a partir da década de 1970 apresentam particularidades fundamentais para compreendermos as transformações edinâmicas regionais em várias dimensões. O presente estudo, caracterizado como uma revisão bibliográfica e documental, objetiva analisar o seu processo de constituição e significado histórico, no contexto do desenvolvimento da região e do País. Debruça-se sobre um conjunto de documentos e, principalmente, de pesquisas realizadas ao longo de mais de três décadas, por pesquisadores de diferentes áreas. Como resultados, pode-se afirmar que o seu surgimento, mesmo reagindo às novas condições sociais e econômicas experimentadas na região, não pode ser explicado apenas a partir delas. Foram decisivos os processos pedagógico-elucidativos desenvolvidos por algumas instituições, nos quais os agricultores puderam construir novas interpretações sobre sua realidade. Atualmente, algumas das velhas questões exigem novas respostas e se colocam no campo dos desafios e deixam em aberto as possibilidades de futuro.
\end{abstract}

Palavras-chave: Movimentos Sociais. Movimentos Populares do Campo. Oeste Catarinense. Lutas Camponesas.

ABSTRACT: The popular social movements of the countryside that emerged in western Santa Catarina in the 1970s present fundamental peculiarities for understanding regional transformations and dynamics in various dimensions. The present study, characterized as a bibliographical and documentary review, aims to analyze its process of constitution and historical significance, in the context of the development of the region and the country. It focuses on a set of documents and, mainly, of research done over more than three decades, by researchers from different areas. As a result one can affirm that its emergence, even reacting to the new social and economic conditions experienced in the region, cannot be explained only from them. The pedagogical-elucidative processes developed by some institutions were decisive, in which farmers were able to construct new interpretations about their reality. Today, some of the old issues require new responses and place themselves in the field of challenges and leave open the possibilities of the future.

Keywords: Social Movements. Popular Countryside Movements. Western Santa Catarina. Peasant Struggles.

RESUMEN: Los movimientos sociales populares del campo que surgieron en Oeste Catarinense, a partir de la década de 1970, presentan particularidades fundamentales para que podamos comprender las transformaciones y dinámicas regionales en diversas dimensiones. El presente estudio, caracterizado como una revisión bibliográfica y documental, objetiva analizar su proceso de constitución y significado histórico, en el contexto del desarrollo de la región y del país. Se basa en un conjunto de documentos y, principalmente, de investigaciones realizadas a lo largo de más de tres décadas, por investigadores de distintas áreas. Como resultados se puede afirmar que su surgimiento, aunque reaccionando a las nuevas condiciones sociales y económicas experimentadas en la región, no puede ser explicado solamente a partir de ellas. Fueron decisivos los procesos pedagógico elucidativos desarrollados por algunas instituciones, en las cuales los campesinos pudieron construir nuevas interpretaciones sobre su realidad. Actualmente, algunas de las antiguas cuestiones exigen nuevas respuestas y se ponen como retos, dejando abierto a las posibilidades de futuro.

Palabras clave: Movimientos Sociales. Movimientos Populares del Campo. Oeste Catarinense. Luchas Campesinas. 


\begin{abstract}
* Doutor em Educação pela Universidade Estadual de Campinas (Unicamp), professor do Programa de Pós-Graduação em Educação da Universidade Comunitária da Região de Chapecó (Unochapecó). Endereço: Rua Clevelândia, 265E, ap. 101 (Edifício Nápoli), Centro, Chapecó/SC, CEP: 89801-560.
\end{abstract}

** Doutora de Ciências Humanas pela Universidade Federal de Santa Catarina (UFSC); professora permanente do Programa de Pós-Graduação em Políticas Sociais e Dinâmicas Regionais da Universidade Comunitária da Região de Chapecó (Unochapecó); professora colaboradora do Programa de Pós-Graduação em Educação da Unochapecó. Endereço: Rua Curitiba, 541D, ap. 302(Edifício Palermo), Bairro Santa Maria, Chapecó/SC, CEP: 89812-150.

*** Doutoranda do Programa de Pós-Graduação em Desenvolvimento Regional no Rio Grande do Sul(PPGDR/RS)da Universidade de Santa Cruz (UNISC). Professora do Curso de Pedagogia da Unochapecó. Militante do MMC. Endereço: Rua Vitório Cadore, 314D, Bairro Efapi, Chapecó/SC, CEP: 89809-719.

1 A Teologia da Libertação, neste contexto, constitui-se como a principal contribuição para a formação dos movimentos sociais populares, orientados por um conjunto de ideias e de uma práxis de transformação da realidade latino-americana acerca da solidariedade da Igreja; do ataque às injustiças e da violência institucionalizada; da prática de uma educação libertadora; da adoção do rumo ao socialismo; da deflagração de um processo de libertação (GUTIÉRREZ, 1976, 1981).

\footnotetext{
2 Ditadura Militar, como resposta à grave situação vivida pelos trabalhadores rurais, posseiros e peões, sobretudo na Amazônia, explorados em seu trabalho, submetidos a condições análogas ao trabalho escravo e expulsos das terras que ocupavam (CPT, 2010).

3 São pequenos grupos, organizados em torno da paróquia (urbana) ou da capela (rural), que reúnem pessoas organizadas pela "comunidade de fé" (eclesiais) e integradas por classes populares (base) que vivem uma comum-união em torno de seus problemas de sobrevivência, de moradia, de lutas por melhores condições de vida, anseios e esperanças libertadoras (FREI BETTO, 1981).
}

\section{INTRODUÇÃO}

Os movimentos sociais populares do campo na região de Chapecó e no Oeste Catarinense, a partir de meados da década de 1970 apresentam particularidades fundamentais para compreendermos as transformações e dinâmicas regionais em várias dimensões, bem como experiências e demandas compartilhadas por populações rurais no Brasil, como decorrência das mudanças conjunturais e estruturais impostas pelo regime militar, pela modernização da agricultura e pela constituição de um processo de redemocratização.

Nesse sentido, no Brasil, e em grande parte da América Latina, movimentos populares urbanos e rurais, heterogêneos em temáticas e demandas, a partir desse contexto, articularam-se em grupos de oposição ao regime militar. Esses movimentos têm como base a Teologia da Libertação ${ }^{1}$, inspirada nas orientações do Concílio Vaticano II e na tradição latino-americana, iniciada pela II Conferência Episcopal de Medellín, realizada na Colômbia em 1968, e, posteriormente, pela terceira, realizada em Puebla, no México, em 1979.

No caso da região de Chapecó e do Oeste Catarinense, a base empírica para pensarmos a constituição dos movimentos sociais populares do campo está assentada em uma estrutura socioeconômica e cultural que caracteriza a formação de um campesinato heterogêneo neste território. Para este estudo, nós nos ateremos a particularidades relativas à formação da pequena produção, vinculada às atividades de agricultores migrantes vindos do Rio Grande do Sul no início do século XX e que, em decorrência do processo de modernização da agricultura, a partir da década de 1970, tiveram seu modo de vida e produção desestruturados. Esse processo culminou na constituição de movimentos sociais específicos, protagonizados por estes pequenos agricultores familiares.

Entre estes movimentos,destacam-se o Movimento de Oposições Sindicais, o Movimento dos Trabalhadores Rurais Sem Terra (MST), o Movimento das Mulheres Agriculturas (MMA) e o Movimento de Atingidos pelas Barragens do Rio Uruguai (MAB). Assentados em uma base organizativa ligada à pequena produção familiar, constituíram-se a partir de estratégias de atuação política e bandeiras de luta específicas e tiveram, como mediação organizativa, o apoio da Igreja Católica progressista, por meio da Comissão Pastoral da Terra $(\mathrm{CPT})^{2}$, das Comunidades Eclesiais de Base (CEBs) ${ }^{3}$ e do Serviço de Assessoria e Informação da Diocese de Chapecó (SAI). Pela sua localização e por sediar essas organizações de ação regional, o município de Chapecó tem-se caracterizado, historicamente, como um polo econômico e político, aglutinando formas organizativas das mais diversas (POLI, 1995, 2008).

A constituição desses movimentos específicos, a partir da crise provocada pela modernização da agricultura no 
4 O ethos camponês ou campesinidade, de acordo com Woortmann (1990), é formado por três aspectos inter-relacionados: terra, trabalho e família.
5 A Via Campesina é um movimento internacional autônomo, pluralista, e multicultural sem nenhuma filiação política ou econômica, que surge em defesa da agricultura sustentável como forma de promover a justiça social e a dignidade, além de se opor fortemente às multinacionais do agronegócio que estão destruindo os bens naturais e as pessoas. Atualmente, reúne cerca de 164 organizações locais e nacionais em 73 países da América, África, Ásia e Europa. Em relação aos movimentos populares do campo da região de Chapecó e Oeste Catarinense, objeto deste estudo, compõem a Via Campesina as seguintes organizações: MST, MMC, MAB e Movimento dos Pequenos Agricultores (MPA). ethos camponês tradicional ${ }^{4}$, teve, portanto, apoio decisivo de setores da igreja católica e da Diocese de Chapecó, por meio, principalmente, do papel desempenhado pelo bispo Dom José Gomes. Este, tendo tomado posse em 1968, passou a organizar na Diocese, a partir de 1973, os grupos de reflexão, em sintonia nacional com a CPT, os quais tinham em vista a discussão de diferentes problemáticas da região. Entre elas, destacam-se: o apoio à criação e sustentação dos Sindicatos de Trabalhadores Rurais, apoio ao movimento em prol do Ensino Superior em Chapecó, a defesa das comunidades indígenas e da Reforma Agrária, a questão das barragens e dos agricultores por elas atingidos, o incentivo e acompanhamento de lideranças feministas em ações nos Sindicatos e na política (STRAPAZZON, 1998; POLI, 1995; UCZAI, 2002).

Desde logo, é preciso demarcar que nosso entendimento sobre os movimentos aqui mencionados encontra fundamentação em Gohn (2008b), ao afirmar que é na ação concreta que esses atores adotam diferentes estratégias, bem como vão alterando suas orientações, seus repertórios e as maneiras pelas quais explicitam as pressões diretas e indiretas. Na medida em que muda a conjuntura, alteram-se as formas de pressões e se recolocam novos cenários de identificação dos atores em luta. É nessa perspectiva que, na atualidade, principalmente a partir de 2013, observa-se um contexto social, político e econômico de manifestações e movimentos sociais no Brasil, com diferentes significados. Neste cenário, os movimentos do campo ligados à Via Campesina ${ }^{5}$ passam a se identificar, enquanto movimentos populares do campo, como estratégia para reafirmação de sua identidade.

Caracterizado metodologicamente como uma revisão bibliográfica e documental, este texto está estruturado em três seções que correspondem aos objetivos propostos. A primeira busca caracterizar os movimentos sociais, a partir de uma periodização e conceitualização no que se refere às abordagens teóricas predominantes, no contexto latino-americano e brasileiro, bem como, caracterizar os movimentos populares do campo. A segunda analisa a estrutura sócio-histórica e econômica que culminou na constituição dos movimentos sociais populares do campo de Chapecó e da região Oeste Catarinense. Por fim, em um esforço de síntese, apresentaremos alguns dos desafios e algumas perspectivas que os movimentos populares têm assumido neste novo contexto social.

\section{CARACTERIZAÇÃO HISTÓRICA E CONCEITUAL}

A complexidade e a multidimensionalidade que envolvem as teorias dos movimentos sociais e ações coletivas na América Latina, a partir dos anos 1970, têm sido objeto de diferentes estudiosos, que trataram de dinâmicas e contextos históricos e empíricos variados, no meio urbano 
e rural. Esta multiplicidade, contudo, não será objeto deste texto. Sobre algumas revisões realizadas acercado tema por estudiosos brasileiros, destacam-se as contribuições de Doimo (1995), Gohn (1995, 1997, 2003, 2008a, 2008b), Scherer-Warren e Krischke (1987) e Scherer-Warren $(1989,1993,2008)$.

No que se refere às teorias dos movimentos sociais na América Latina, sua constituição e trajetória estão vinculadas, segundo Scherer-Warren (1993) e Gohn (1997), a diferentes paradigmas associados ao desenvolvimento latino-americano, em suas diferentes dimensões e ao pensamento social latino-americano e suas articulações com o pensamento teórico internacional, especialmente, o europeu.

Ao se referir ao paradigma latino-americano, Gohn (1997) trata sobre suas especificidades e lança hipóteses sobre o porquê do uso dos paradigmas europeus nos estudos sobre os movimentos sociais na América Latina e no Brasil. Afirma que as teorias europeias eram consideradas mais críticas e articuladas aos pressupostos da nova esquerda constituída no final dos anos 1970 e no início dos anos 1980, as quais influenciaram os estudos acadêmicos e as ações militantes inicialmente por meio do paradigma marxista.

De forma genérica, essa trajetória pode ser periodizada em quatro momentos que correspondem a tendências paradigmáticas, o que não significa que em cada fase haja o desaparecimento das tendências anteriores.

No primeiro momento, que se estende de meados do século XX até início dos anos 1970, a teoria social latino-americana teve o predomínio de perspectivas marxistas, nas quais predominavam análises macroestruturais, que abordavam a classe social como sujeito privilegiado da transformação histórica, com ênfase na estrutura econômica (SCHERER-WARREN, 1993).

O fundamental no pensamento de Marx foi ter dado à categoria "totalidade" um lugar central, ao examinar o agir humano como um conjunto que conecta dialeticamente várias práxis: teórica, produtiva ou econômica e político-ideológica. A articulação entre essas práxis criou o espaço necessário para se colocar a ciência engajada aos movimentos sociais (SCHERER-WARREN, 1989, p. 136).

Gohn (1997) afirma que o paradigma marxista tem sido visto, de forma generalizada, erroneamente, como sinônimo de análise do movimento operário e, como decorrência, pertencente ao universo do "antigo" que se contraporia ao "novo". Outra distorção frequente é a generalização deste paradigma em uma só teoria, sem distinção de abordagens ortodoxas e heterodoxas.

Entre as teorias marxistas não ortodoxas, destaca-se a proposta de Thompson $(1981,1987)$,a qual permite compreender fenômenos políticos e sociais da contemporaneidade, dentre os quais os movimentos sociais, pelo viés de que a sociedade deve ser explicada não somente a partir das relações de produção como determinantes das 
demais esferas da vida social. Ao contrário, a compreensão do desenvolvimento social precisa considerar também as experiências concretas e simbólicas dos sujeitos coletivos, que se constroem continuamente, a partir da apropriação de conhecimentos e de vivências que constituem a base da prática política. Esta, por sua vez, irá orientar a construção de valores, de projetos coletivos, bem como, a configuração das identidades políticas.

Em Thompson, a experiência desempenha um papel mediador entre a consciência e o ser social. Por meio de experiências, sujeitos coletivos se organizam e constroem a sua consciência social por meio da ação concreta e do percurso de suas histórias, mediadas por interesses e objetivos de um projeto coletivo, o qual é constituído a partir da necessidade e da consciência de mudar sua condição social, econômica e cultural. Nessa perspectiva, é possível, por intermédioda análise empírica dos diferentes movimentos sociais do campo, identificar a classe em sua amplitude e singularidade, mediante observações de experiências concretas em contextos reais.

As reflexões de Thompson, a partir de seus pressupostos teóricos e da análise empírica, permitem-noscompreender a dinamicidade que envolve os movimentos sociais, como sujeitos coletivos que, por meio de experiências, se constroem continuamente, a partir da apropriação de conhecimentos e de vivências que constituem a base de suas práticas políticas, projetos coletivos, valores, bem como a configuração de identidades políticas. Nessa direção:

O movimento social, como um sujeito social coletivo, não pode ser pensado fora de seu contexto histórico e conjuntural. As identidades são móveis, variam segundo a conjuntura. Há um processo de socialização da identidade que vai sendo construída. [...] a identidade política dos movimentos sociais não é única: ela pode variar em contextos e conjunturas diferentes. E muda porque há aprendizagens, que geram consciência de interesses. (GOHN, 2008a, p. 444).

No segundo momento, relativo à década de 1970, são introduzidos na análise novos elementos, deslocando a ênfase da determinação econômica (sem excluir esta dimensão) a outros fatores como a ação da sociedade civil, em seus múltiplos fatores (econômicos, políticos e culturais) (SCHERER-WARREN, 1993).

Em umterceiro momento, a partir da primeira metade da década de 1980, a categoria movimento social surge como referência para estudos de grupos específicos e de seus modos de fazer política, sugerindo-se que "uma nova cultura política popular e de base estaria sendo gerada na América Latina" (SCHERER-WARREN, 1993, p.17), onde as categorias de sujeito popular e de movimento popular caracterizam-se em diferentes níveis e formas de 
organização, tais como os movimentos urbanos, as comunidades eclesiais de base, as lutas pela terra e moradia, os movimentos de mulheres, ecologistas, sindicais, étnicos, de direitos humanos, entre outros. Para Gohn (1997), esse período se caracteriza pela redemocratização, em que os movimentos sociais de diferentes tipos ganham visibilidade através da mobilização popular da sociedade civil, tendo em vista a luta pela garantia de direitos sociais coletivos por parte de grupos sociais oprimidos e discriminados.

No quarto momento, que tem início nos anos 1990, destacam-se novos temas, decorrentes de transformações nas realidades internas dos países latino-americanos, como os movimentos de democratização política e reformas institucionais e externas, a partir de interconexões entre o local e o global, o micro e o macro, o comunitário e o supranacional. Sugere-se, então, a ocorrência de práticas políticas articulatórias entre ações localizadas e redes de movimentos, com a influência das tecnologias de informação e dos meios de comunicação nas formas de organização da sociedade civil, as quais abrangem desde propostas alternativas de vida social, até as preocupações de nações e povos em torno de problemas comuns (SCHERER-WARREN, 1993). Para este período, Gohn (2008a) destaca mudanças ocorridas no mundo do trabalho através da reestruturação produtiva e de políticas econômicas fundamentadas no neoliberalismo, que ocasionaram o aumento da informalidade no trabalho, o desemprego estrutural e o enfraquecimento de sindicatos e movimentos sociais.

Essa periodização, ao se caracterizar como uma tipologia de características predominantes e paradigmas em determinados contextos históricos, não descarta a possibilidade analítica e empírica de que tais elementos se apresentem de forma articulada e híbrida nas estratégias e propostas políticas dos movimentos sociais na atualidade, rompendo com perspectivas deterministas, unilineares e ortodoxas.

Nesse sentido, Gohn (2003), ao se referir aos movimentos sociais, os compreende como conformações históricas, sociais e políticas que sempre existiram e continuarão a existir, na medida em que não seguem um padrão ou linearidade racional, pois tais sujeitos coletivos se constroem continuamente, "[...] no processo de luta, perante a sociedade civil e política; não se trata de um reconhecimento outorgado, doado, uma inclusão de cima para baixo" (GOHN, 2008a, p. 444).

No que se refere aos movimentos sociais do campo, no Brasil, que surgem a partir de meados dos anos 1970 e início dos anos 1980 do século XX, devem ser compreendidos, segundo Scherer-Warren e Krischke (1987), pela forma como se organizam e pelo modo como encaminham suas lutas, diferentemente de outros contextos. Tais formas, de acordo com Scherer-Warren (1993), caracterizam-se pela participação ampliada das bases e pela democracia direta, opondo-se ao autoritarismo, à centralização do poder e ao uso da violência física. 
Essa reflexão possibilita compreender as mudanças, no sentido de como os próprios movimentos vão alterando suas concepções, enquanto identidade social, no sentido de garantir não apenas sua legitimidade, mas de explicitar claramente as razões, as motivações e os significados de suas lutas, justificando porque, neste novo contexto, os mesmos movimentos sociais do campo passam a assumir-se como movimentos populares do campo.

Na América Latina e no Brasil, a partir de meados dos anos 1970, os movimentos sociais no campo tiveram na Teologia da Libertação, através de alguns setores da igreja progressista e nas lideranças de esquerda, importantes mediadores na busca de uma sociedade mais justa e igualitária. A utopia da libertação, segundo Scherer-Warren (1993), implica uma crítica das condições de desigualdade social, em um projeto de mudança fundamentado no igualitarismo socioeconômico, opção preferencial pelos pobres e luta contra as variadas formas de opressão, pressupostos ideológicos básicos que orientaram a constituição dos diferentes movimentos populares do campo a partir desse contexto.

Os pequenos agricultores, nesse contexto, a partir de suas variadas representações e identidades (sem-terra, atingidos por barragens, mulheres trabalhadoras rurais, entre outras), segundo Picolotto (2007, p.47), passaram a se organizar em movimentos sociais, "[...] para lutar contra a expropriação de seus meios de produção e encontrar alternativas para a continuação de sua reprodução social”.

Os diferentes movimentos populares do campo, anteriormente citados e constituídos no Sul do Brasil têm, ao longo de suas trajetórias, protagonizado importantes experiências socioeconômicas que contribuíram para transformar as estruturas hegemônicas mediante a viabilização de alternativas nas formas de produzir e viver (práticas agroecológicas, cooperação, autogestão).

A partir de meados dos anos 1990, ampliam suas estratégias e formas de atuação para níveis organizacionais em redes, a exemplo da Via Campesina, que, em sua abrangência nacional e internacional,agrega variados movimentos e organizações sociais. Segundo Picolotto (2007, p.49), a Via Campesina, no Brasil, busca construir uma identidade e um projeto para o campesinato, em relação "[...] às alternativas de resistência camponesa ao capitalismo e às possibilidades de sua superação através da construção de novas bases socioeconômicas [...]", e na produção de “[...] um projeto de transformação social a partir dos elementos culturais e materiais do campesinato".

O porvir de novas identidades coletivas, de projetos e articulações políticas dos movimentos populares do campo são indicadores das trajetórias percorridas historicamente e que têm gerado novas dinâmicas sociais nas bases dos movimentos, elementos estes que serão tratados nas próximas sessões. 


\section{MOVIMENTOS POPULARES DO CAMPO NO OESTE CATARINENSE}

Conforme o enfoque descrito,desde o final dos anos 1970 o Oeste Catarinense passou a ser sacudido por um processo crescente de mobilização das populações do campo, aglutinadas em torno de um conjunto de identidades desenvolvidas a partir de especificidades presentes no interior dessas populações. A análise desse fato, à luz da contribuição teórica de Thompson, indica que para esse processo contribuíram tanto fatores que se podem denominar de estruturais como fatores de natureza política e cultural. Dentre estes, destaca-se a existência de processos pedagógico-elucidativos que passaram a pôr em circulação novas interpretações sobre o significado das condições sociais e econômicas vigentes, interagindo com a cultura e a consciência afetiva e moral dessa população(THOMPSON, 1981; VENDRAMINI, 2012; POLI, 1995).

Do ponto de vista estrutural, é importante destacar que, nessa época, momento em que passou por um processo de modernização e industrialização, o Oeste Catarinense era habitado, predominantemente, por descendentes de imigrantes italianos, alemães e poloneses, oriundos do estado do Rio Grande do Sul, que praticavam uma agricultura de base familiar, voltada à produção de alimentos para o mercado nacional (POLI, 1995; WERLANG, 2002). Dedicavam-se, principalmente, à produção e à comercialização de produtos como feijão, arroz, trigo e até mesmo galinhas, em caráter complementar à produção de suínos, principal fator de desenvolvimento da região, desde os anos 1940. Aliado a isso, é preciso mencionara existência de uma considerável produção de milho, o qual era transformado em alimentação animal, no interior das próprias unidades camponesas de produção (POLI, 2002).

A partir da segunda metade dos anos 1970, contudo, a região passou a experimentar transformações profundas, as quais modificaram substancialmente a estrutura produtiva vigente e alteraram as condições de reprodução dessa agricultura de base familiar. Para isso, concorreram três processos econômicos principais. Em primeiro lugar, o avanço do processo de industrialização, com base na agroindústria, o qual promoveu uma crescente submissão da agricultura familiar à lógica industrial, além de gerar uma significativa demanda de mão de obra no espaço urbano, estimulando o êxodo rural. Em segundo lugar, o processo de modernização da agricultura que, em vista da obtenção de maiores índices de produtividade bem como em busca da modificação dos padrões de qualidade dos produtos produzidos, passou a exigir a incorporação crescente de equipamentos e insumos de origem industrial ao processo de produção agrícola. Por fim, o esgotamento da fronteira agrícola, o qual concorreu para a crescente dificuldade de reprodução social da agricultura de base familiar, forçando o deslocamento populacional para outros espaços, 
incluindo o êxodo rural(POLI, 1995, 2008; GRAZIANO DA SILVA, 1996).

Dentre os três processos citados, a modernização da agricultura foi, sem dúvida, o que mais diretamente concorreu para a inviabilização da continuidade das formas tradicionais de produção da agricultura familiar no Oeste Catarinense. E essa inviabilização se fez sentir, nessa região, por meio de dois fatores principais: o endividamento dos agricultores junto ao setor bancário e a crise da suinocultura (POLI, 1995).

O surgimento de uma série de estímulos à melhoria de equipamentos e instalações nas propriedades e à modernização das técnicas de produção (o emprego de sementes híbridas, a melhoria das raças e das técnicas de manejo e alimentação na produção de suínos, a utilização de insumos de origem industrial, como fertilizantes, defensivos agrícolas e outros), ocorreu paralelamente à abertura de linhas de crédito bancário acessíveis aos pequenos produtores rurais (GRAZIANO DA SILVA, 1982, 1996; POLI, 1995).

A esses estímulos, por outro lado, correspondeu um aumento nas exigências de qualidade dos produtos e das expectativas de produtividade, inviabilizando as formas tradicionais de produção. A diminuição dos ganhos unitários sobre cada produto deveria ser compensada por ganhos de produtividade. Ou seja, o mercado dos produtos agrícolas passou a trabalhar com expectativas de produtividade bem superiores àquelas que a grande maioria dos camponeses da região conseguiam, em média, atingir (GRAZIANO DA SILVA, 1982; POLI, 1995; MATOS; PESSOA, 2011).

A forma de viabilizar a implementação de tais melhorias foi a contratação de financiamentos junto ao setor bancário. Se, incialmente, os juros eram atrativos, aos poucos as consequências do processo inflacionário se fizeram sentir e muitos camponeses passaram a ter grandes dificuldades para quitar suas dívidas, o que os induziu a vender bens e, em muitos casos, a própria terra. Esse fator, aliado à oscilação dos preços da carne suína e ao fato de que, mesmo após a realização de melhorias nas propriedades, muitos camponeses continuavam a não atingir níveis competitivos de produção e produtividade, ocasionou uma forte crise na agricultura familiar tradicional e uma crescente dificuldade de reprodução social desse modelo (POLI, 1995).

Foi nesse contexto de profundas transformações da realidade regional que surgiram, no início da década de 1980 , os intensos movimentos sociais no campo de que trata o presente estudo, cuja repercussão política ultrapassa em muito as fronteiras do Oeste Catarinense, ganhando visibilidade em nível nacional e até internacional.

Naquele momento, muitas famílias camponesas estavam empobrecidas e com dificuldades para produzir suas condições de vida. Principalmente, passaram a ter dificuldades crescentes para reproduzir-se socialmente, isto é, de garantir a implantação de novas unidades produtivas para os seus filhos, deixando estes sem alternativas de continuação 
no campo. Passaram, então, a conviver com a ameaça à sua própria condição camponesa (POLI, 2008).

As formas de reagir frente a tais condições foram diversas e relacionadas à interpretação dessas experiências, no contexto de sua cultura e da sua consciência afetiva e moral (POLI, 1995; THOMPSON, 1981). Para isso, na perspectiva já indicada de Thompson (1981), para além das causas ditas estruturais, contribuíram fatores de natureza política e cultural.

Do ponto de vista cultural, é importante registrar que, como indicou Poli (1995), algumas características sociais e culturais dessa população favoreceram o seu processo de mobilização e de organização política. Destaque-se, por exemplo, a estabilidade dos grupos (familiares e comunidades), favorecida tanto pela propriedade da terra, quanto pela existência de uma organização social que articulava todos os indivíduos e grupos familiares em comunidades, as quais centralizavam certas funções e serviços de interesse coletivo. Essa tradição de organização comunitária, centralizada em torno da capela, que abarcava e geria os interesses coletivos referentes a diferentes aspectos da vida cotidiana (escola, igreja, esporte, lazer, assistência, informações, entre outros), possibilitou o desenvolvimento de práticas associativas e de organização de grupos em torno de objetivos comuns (participação, discussões, divisão de tarefas, cooperação, eleições, representações de interesses coletivos e exercício de liderança). Tais práticas parecem ter sido fundamentais para a constituição de identidades e de organizações de caráter coletivo, necessárias à organização desses movimentos sociais.

Na mesma perspectiva, a intensidade da fé religiosa e das práticas dela decorrentes constituiu-se como um traço cultural significativo, tanto no sentido de motivar e estimular a constituição de espaços coletivos de interação e comunicação (comunidades), quanto no sentido de constituir um conjunto de valores ético-morais compartilhados por essa população. Esse espaço valorativo comum constituiu-se no substrato cultural a partir do qual estabeleciam suas relações com situações, agentes e discursos com os quais passaram a se defrontar e interagir (POLI, 1995).

Contudo, coerente com essa perspectiva de análise, para a compreensão do surgimento desses movimentos sociais, a percepção, pelos camponeses, das novas condições históricas que desestruturaram suas condições de vida e de produção, bem como, a consideração dos fatores subjetivos anteriormente indicados, são condições indispensáveis, mas não suficientes. Ou seja, mesmo contando com algumas condições prévias favoráveis ao processo de mobilização, este não seria possível sem a ocorrência de avanços no processo de entendimento e sem que ocorressem mudanças nas estruturas normativas dessa população (POLI, 1995; TARELHO, 1988).

Essa afirmação pode ser fundamentada na tese habermasiana de que a evolução social não pode ser explicada 
apenas com base no desenvolvimento das forças produtivas, sem considerar os processos de aprendizagem que ocorrem ao nível das estruturas normativas, os quais, ao apontarem novos parâmetros para a solução dos conflitos, tornam possíveis novas relações de produção. Nesse sentido, Habermas (1989) afirma que o desenvolvimento das estruturas normativas funciona como um abridor de caminhos para a transformação das relações sociais. Ou seja, a possibilidade de produção de soluções novas e a emergência de novas formas de reagir frente aos desafios colocados pelas condições histórico-estruturais passam, necessariamente, pela existência de processos de aprendizagem ao nível do agir comunicativo voltado ao entendimento, do saber prático-moral e das estruturas normativas(HABERMAS, 1989, 1990; POLI, 1995).

Com base nesse entendimento, pode-se afirmar que as novas condições histórico-materiais, decorrentes da modernização da agricultura, bem como, as características socioculturais da população envolvida, embora amplamente favoráveis ao processo de mobilização e organização desses movimentos sociais, por si só, não os teriam desencadeado. Foi necessária a existência de processos de aprendizagem que possibilitaram a esses camponeses alcançar novos níveis de consciência. Nessa perspectiva, o patrimônio cultural da população em questão funcionou apenas como tendência ou predisposição, podendo, inclusive, por vezes, determinar decisões e ações em sentido contrário à mobilização e à organização. Como exemplo, podem-se citar os casos em que, em nome da tradição e da fé religiosa, muitos camponeses condenaram o envolvimento de agentes religiosos com questões de natureza política, propondo uma separação absoluta entre prática religiosa e os problemas cotidianos (POLI, 1995).

A possibilidade do surgimento de movimentos sociais entre os camponeses do Oeste Catarinense, a partir do final dos anos de 1970, enquanto resposta qualitativamente nova frente aos desafios impostos pelas novas condições de vida e de produção, desencadeadas a partir da desestruturação do seu processo tradicional de produção, no contexto de sua cultura e do seu modo de vida, implicou, então, na existência de processos pedagógico-elucidativos que lhes possibilitaram atingir novos níveis de entendimento e consciência sobre essa realidade (POLI, 1995).

Tais processos pedagógico-elucidativos foram desencadeados, em Chapecó e região, a partir do momento em que setores da igreja passaram a mudar sua perspectiva de ação, implementando algumas práticas pastorais que favoreceram a discussão e a compreensão das condições histórico-materiais vividas e a tematização das relações cotidianas, modificando tanto a forma de compreender a realidade, quanto o modo de compreender a relação entre a vivência religiosa e as práticas cotidianas (POLI, 1995; STRAPAZZON, 1998; ORO, 1992). 
A evangelização, a partir de então, assumiu a perspectiva de libertação, entendida como superação de todas as formas de opressão, relacionando-se, portanto, com os problemas da vida cotidiana. Ao invés de apenas esperar a salvação que viria após a morte, os cristãos passaram então, a ser desafiados a construir o reino de Deus aqui na terra, o que, por sua vez, se confundia com a construção de um novo projeto de sociedade. A estratégia sugerida para tanto foi a organização e a luta numa perspectiva de classe. [...] A vivência da fé passou a ser um espaço de tematização dos problemas ligados à vida cotidiana, através do estudo e da reflexão dos problemas sociais concretos e suas soluções. [...] Tais práticas pastorais caminharam, portanto, na perspectiva de constituição de sujeitos históricos capazes de assumir a condução do próprio destino. (POLI, 1995, p. 353).

As ações desencadeadas buscaram a criação e/ou o redimensionamento de espaços de interação nas comunidades. Nessa visão, por exemplo, um dos espaços mais tradicionais de interação e vivência religiosa (o encontro de orações aos domingos, realizado nas comunidades) foi transformado e passou a ser dotado de novos significados. As rezas repetitivas (reza do terço, por exemplo) deram lugar ou, ao menos, abriram espaços a orações e reflexões sobre temas articulados com as situações vividas pelos seus participantes. Novos espaços interativos também foram criados nessa perspectiva. Cita-se, por exemplo, os grupos de reflexão ou círculos bíblicos e também os cursos de formação de lideranças. Em todos eles, a fé religiosa passa a ser articulada à análise e reflexão sobre as novas situações vividas pela comunidade, embasadas por um discurso crítico-interpretativo, que colocava em circulação novos conhecimentos e informações sobre a realidade. Os dados sobre a estrutura fundiária no Brasil pode ser citado como um exemplo emblemático desses conhecimentos que passaram a ser apropriados pela população camponesa, por meio desses processos pedagógico-elucidativos que ocorriam em profunda articulação com o patrimônio cultural da população (POLI, 1995).

A existência desses espaços comunicativos foi um elemento central para o surgimento do processo de mobilização e organização dos movimentos sociais aqui estudados. Sua importância está ligada, em primeiro lugar, à possibilidade [...] [de] veiculação de informações e elementos do processo de organização social e suas relações, até então inacessíveis aos camponeses. Também permitiu sua discussão e análise, mediante a veiculação de um discurso crítico, portador de novas interpretações do processo social e suas relações. (POLI, 1995, p. 355). 
Foi nesse contexto que, como parte de um processo complexo em que se articulam as transformações das condições materiais de vida, o patrimônio cultural dos camponeses e os processos educativos desencadeados nos espaços e momentos de práticas religiosas, foram sendo gestadas práticas organizativas que culminaram na criação, organização e expansão de movimentos sociais envolvendo populações camponesas no Oeste Catarinense, no final dos anos 1970 e início dos anos 1980 do século XX.

É indispensável destacar que, aos poucos, tais movimentos passaram a agir com crescente autonomia em relação à igreja e que outras instituições contribuíram para o seu surgimento. Suas próprias práticas, reflexões e ações passaram a servir de referência para a população direta ou indiretamente envolvida. Além disso, passaram a desenvolver seus próprios processos formativos e de reflexão sobre a realidade que os envolvia, base importante para o fortalecimento de suas lideranças, assim como para a conquista e a formação de novos militantes (POLI, 1995).

Com o passar do tempo, seus impactos culturais e políticos passaram a extrapolar as fronteiras da realidade local/regional, bem como os limites internos dos próprios movimentos e da população que lhe serviu de base social. Embora sejam necessários novos estudos a respeito, podemos afirmar que é inegável que os discursos e as práticas emanados desses movimentos sociais contribuíram, de modo significativo, para o surgimento de práticas organizativas em outras regiões e segmentos populacionais, como também influenciaram a cultura política de amplos segmentos populacionais de Chapecó e da região do Oeste Catarinense.

\section{DESAFIOS, PERSPECTIVAS, RUMOS DA LUTA CAMPONESA A PARTIR DOS MOVIMENTOS POPULARES DO CAMPO}

Diante da realidade até aqui descrita, podemos observar que a reafirmação dos movimentos populares do campo, no plano de renovação das utopias por direitos sociais, por cidadania inconclusa (CARVALHO, 2005) e pela democratização da sociedade, tem ocupado lugar privilegiado nas lutas populares camponesas. Ou seja, enquanto espaços coletivos de reivindicação de direitos, a luta em defesa da democracia e efetivação de sujeitos (BEZERRA NETO, 1999) está (re)colocada como desafio em tempos atuais.

A visibilidade de uma socialização política de saberes, de valores e aprendizados, que são fundamentais para o avanço do processo de constituição de outras identidades sociais, construídos historicamente, também está em pauta, principalmente porque,nesse novo contexto, urge repensar as práticas educativas e a educação de modo geral. O que se pode observar é que os movimentos populares do campo constituem-se como um lócus, por excelência, de 
6 A mudança da denominação de Movimento de Mulheres Agricultoras (MMA) para Movimento de Mulheres Camponesas (MMC) é resultado de um longo processo de lutas articuladas nacionalmente que ocorreu mais fortemente a partir de 2000. Os movimentos autônomos de mulheres trabalhadoras rurais existentes nos estados discutem a importância de criar um movimento nacional. O Congresso Nacional de Consolidação do Movimento de Mulheres Camponesas (MMC) foi realizado em Brasília, no período de 5 a 8 de março de 2004, "após intenso processo de estudo com dirigentes e grupos de base em 19 estados" (MMC/SC, 2008, p.19). Em Santa Catarina, a sigla MMC do Brasil foi oficializada através da $9^{\text {a }}$ Assembleia realizada em Itapiranga/SC, em novembro de 2004. elaboração de determinados tipos de pensamento, que fundamentam uma perspectiva de educação problematizadora (FREIRE, 2007), através do exercício da dialogicidade. É nesse contexto, por exemplo, que se origina a perspectiva da educação do campo que se apresenta tanto como possibilidade, quanto como desafio.

Nessa perspectiva, alguns estudos explicitam temáticas desafiadoras. Dentre eles, podem-se destacar: Caldart (2004) e Bezerra Neto (2003), que tratam sobre a proposta pedagógica do MST; Beltrame (2000), que analisa aspectos importantes para a discussão em torno do processo de formação e prática de professores em escolas de assentamento de reforma agrária do MST. Isto se estende para os espaços formativos internos que estão sendo retomados, com força, por parte dos movimentos. Bezerra Neto (1999) também aborda as práticas educativas no Movimento dos Trabalhadores Rurais Sem Terra. Já os estudos de Silva (2003) retratam que a forma didática como a vida vai sendo elaborada no seu cotidiano, expressa através da Mística elaborada em escolas do MST, mas presente nos demais movimentos populares do campo e da cidade, adquire relevância e está colocada enquanto sinalização para uma perspectiva de vida digna.

Dentre os desafios, destaca-se, ainda, a necessidade permanente de pensar a relação educação e trabalho, conforme demonstram os estudos elaborados por Machado (2003), entre outros.

O Movimento de Mulheres Camponesas (MMC) ${ }^{6}$, que luta pela igualdade e pela valorização das mulheres, tem se destacado na luta por direitos e em defesa da Previdência Pública, Universal e Solidária. Luta contra a violência e pela humanização da sociedade. Tem assumido a defesa de um Projeto Popular e Camponês de Agricultura, em que as sementes crioulas são compreendidas como patrimônio da humanidade e devem estar em primeiro plano. Em 2007, o MMC lançou a Campanha Nacional pela Produção de Alimentos Saudáveis, considerando que:

A artificialização da agricultura pelo crescente uso de insumos de origem industrial, a agroindustrialização dos alimentos, a padronização mundial dos hábitos alimentares da população e a manipulação industrial para a oferta de alimentos com sabores, odores e aparências similares aos naturais, aliados ao aumento da oligopolização dos controles corporativos das cadeias produtivas alimentares, nos indica, entre outros fatores, que, inversamente à construção de uma soberania alimentar, se caminha para uma tirania da dieta alimentar, homogeneizada e manipulada, em busca apenas de altos lucros para as grandes corporações agroindustriais. Sendo provável que até 2050 a população mundial aumente dos atuais 6,3 bilhões para mais de 9 bilhões, tudo leva a crer que a produção agrícola precisará crescer em 70\% na oferta 
de alimentos para a sobrevivência da humanidade, segundo o Fundo Internacional para Desenvolvimento da Agricultura. Ora, essa perspectiva coloca em aberto a expansão do agronegócio internacional. Daí que a busca pela apropriação de terras agricultáveis no Brasil não apenas compromete os biomas no país como faz do seu povo, em particular os camponeses, povos indígenas, ribeirinhos, quilombolas e extrativistas, meros objetos a serem descartados de seus territórios para darem lugar aos interesses de lucro do agronegócio. (STEDILE; CARVALHO, 2011, p. 5).

Daí o desafio não apenas de lutar por uma Política Pública que assegure a dignidade da vida no campo e na cidade, mas centralmente por mudanças estruturais que possibilitem outra perspectiva de campo e de cidade. Pacheco (2002), referindo-se ao projeto para a agricultura pensado e proposto pelo MMC, afirma:

O Movimento de Mulheres Camponesas, por exemplo, defende um projeto popular para a agricultura, através da agroecologia, da preservação da biodiversidade, do uso das plantas medicinais, da recuperação das sementes como patrimônio dos povos a serviço da humanidade, da alimentação saudável como soberania das nações, da diversificação da produção e da valorização do trabalho das mulheres camponesas. Sublinham a necessidade de fortalecer experiências de resistência para a construção desse projeto. Relacionam esta pauta com o desafio de enfrentar a cultura patriarcal machista, com suas formas de opressão, discriminação, subordinação e culpa impostas a mulheres e pobres. (PACHECO, 2002, p.17).

Tais questões ganham expressão através da articulação mundial de camponeses e camponesas. A Via Campesina busca consolidar a unidade da luta camponesa diante da diversidade de bandeiras existentes entre os movimentos populares, posicionando-se contrariamente às formas pelas quais tem se revelado o capital em nível mundial nestes últimos tempos.

A Via Campesina se revelou como um ator principal nas lutas populares internacionais contra o neoliberalismo que, entre outras coisas, exigem responsabilidades das agências inter-governamentais [sic], enfrentam e se opõem ao controle corporativo sobre os recursos naturais e a tecnologia, e defendem a soberania alimentar. Além disso, desempenhou um papel destacado em campanhas de grande polêmica política, como, por exemplo, as dirigidas contra a OMC, contra os gigantes corporativos mundiais, como o McDonalds, e contra os organismos geneticamente 
modificados (OGM) e as multinacionais que os fomentam, como a Monsanto. (BORRAS, 2004, p. 3).

Essa articulação incorpora, em si, uma dinâmica social que está em permanente mudança. Isso se expressa pela diversidade de atores sociais e pelas formas de articulação que vão sendo criadas e recriadas em diferentes momentos históricos. Nesse processo, os movimentos vão se (re)configurando.

O MPA, não mencionado anteriormente, surgiu no Sul do Brasil em 1996, durante uma seca prolongada em que os agricultores perderam toda a sua produção de alimentos. O período se caracterizava também por uma crise no movimento sindical e de abandono da pequena agricultura por parte do Estado brasileiro. Entre seus objetivos, está a produção de comida saudável para as próprias famílias e também para todo o povo brasileiro. A soberania alimentar do nosso país se configura como um dos grandes desafios no contexto atual, principalmente na luta contra os agrotóxicos. Há um entendimento de que, na busca pelo resgate da identidade e da cultura camponesa, respeitando as diversidades regionais que se efetivam nas lutas de resistência e enfrentamento ao capital, estão as grandes perspectivas desses movimentos populares.

Atualmente, os movimentos populares do campo compreendem e articulam a luta pela soberania alimentar, pela agroecologia, por reforma agrária e urbana entre outras reformas estruturais. Ou seja, as bandeiras de luta desses movimentos asseguram suas especificidades e, ao mesmo tempo, propõem ações comuns.

Nesse cenário complexo, para construir perspectivas de unidade e unificação das lutas, integrando campo e cidade, fazem-se necessárias ações cada vez mais voltadas para a pluralidade de povos, culturas, cosmovisões, sonhos e utopias. Há de se ressignificar a formação integral de cada organização e de instâncias mais amplas dos movimentos e das organizações no campo e na cidade.

\section{CONSIDERAÇÕES FINAIS}

Algumas das velhas questões exigem novas respostas que se colocam no campo dos desafios: como enfrentar a violência e criminalização no campo que, além de se intensificar, se apresenta com requintes de crueldade e barbárie? Como resolver questões acerca da terra/território, considerando, principalmente, a luta pela demarcação das terras indígenas, quilombolas e populações tradicionais? Como não separar estas dimensões da luta incessante por reforma agrária ampla e popular, da luta pela soberania alimentar e alimentação saudável, sem o uso de agrotóxicos e de sementes transgênicas? Nesse contexto, incluem-se também as questões mais conjunturais, como a defesa da Previdência, do petróleo e contra a violência. Como assegurá-las e torná-las efetivas? 
Pensar o contexto atual do Oeste Catarinense considerando a presença dinâmica e atuante dos movimentos populares do campo implica, necessariamente, demarcar um processo histórico, dinâmico, gradativo, conflitivo e permanente que possibilita a compreensão de que, mesmo quando muda o contexto das lutas e se alteram os seus repertórios, a perspectiva mais ampla da luta histórica dos camponeses segue em marcha. Faz-se necessário, isto sim, realizar leituras e interpretações dessas diferentes faces da realidade, de modo permanente, por meio da produção/ apropriação de outros saberes, alertados por tais movimentos. Saberes diversos, saberes populares, saberes contra-hegemônicos. A busca por respostas sempre renovadas e contemporâneas a esses desafios históricos do campesinato encontram nos movimentos populares não apenas espaços para sua efetivação, mas concretude nas formas de viabilizar os sentidos da sobrevivência. O contexto não é novo, é diferente! As bandeiras, sim, são renovadas a cada novo momento, mas a perspectiva histórica mais ampla não se modifica fundamentalmente, visto que é calcada na luta pela própria dignidade humana, pela superação de todas as formas de opressão, pela igualdade de direitos e por um mundo mais justo, sustentável e solidário. Dimensão esta que faz do Oeste Catarinense partícipe na construção de outro mundo possível.

\section{REFERÊNCIAS}

BELTRAME, Sonia Aparecida Branco. MST, professores e professoras: sujeitos em movimento. 2000. $244 \mathrm{f}$. Tese (Doutorado em Educação) - Programa de Pós-Graduação em Educação, Universidade de São Paulo, São Paulo, 2000.

BEZERRA NETO, Luiz. Avanços e retrocessos da educação rural no Brasil.2003. $221 \mathrm{f}$. Tese (Doutorado em Educação) - Programa de Pós-Graduação em Educação, Universidade Estadual de Campinas, Campinas, 2003.

BEZERRA NETO, Luiz. Sem-terra aprende e ensina: estudo sobre as práticas educativas do movimento dos trabalhadores rurais. Campinas: Autores Associados, 1999.

BORRAS, Saturnino. La Via Campesina: un movimiento en movimiento. Amsterdã: Transnational Institute, 2004.

CALDART, Roseli Salete. Por uma educação do campo: traços de uma identidade em construção. In: ARROYO, Gonzalez Miguel; CALDART, Roseli Salete; MOLINA, Monica Castagna (Org.).Por uma educação do campo. Petrópolis: Vozes, 2004. p. ?

CARVALHO, José Murilo de.Cidadania no Brasil: o longo caminho. 7. ed. Rio de Janeiro: Civilização Brasileira, 2005. 
COMISSÃO PASTORAL DA TERRA. Histórico. 2010. Disponível em: <http://www.cptnacional.org.br/index. php/sobre-nos/historico>. Acesso em: 30 jun. 2016.

DOIMO, Ana Maria. A vez e a voz do popular: movimentos sociais e participação política no Brasil pós 70. Rio de Janeiro: Relume Dumará; ANPOCS, 1995.

FREI BETTO. O que é comunidade eclesial de base. 1981. Disponível em: <http://www.dhnet.org.br/direitos/ militantes/freibetto/livro_betto_o_que_e_cebs.pdf $>$. Acesso em: 30 jul. 2016.

FREIRE, Paulo. Pedagogia da autonomia: saberes necessários à prática educativa. São Paulo: Paz e Terra, 2007.

GOHN, Maria da Glória. História dos movimentos e lutas sociais: a construção da cidadania dos brasileiros. São Paulo: Loyola, 1995.

GOHN, Maria da Glória. Teorias dos movimentos sociais: paradigmas clássicos e contemporâneos. São Paulo: Loyola, 1997.

GOHN, Maria da Glória. Movimentos sociais no início do Século XXI: Antigos e novos atores. Petrópolis: Vozes, 2003.

GOHN, Maria da Glória.Abordagens teóricas no estudo dos movimentos sociais na América Latina. Caderno CRH, Salvador, v. 21, n. 54, p. 439-456, set./dez. 2008a.

GOHN, Maria da Glória. O protagonismo da sociedade civil: movimentos sociais, ONGs e redes solidárias. 2. ed. São Paulo: Cortez, 2008b.

GRAZIANO DA SILVA, José. A modernização dolorosa: estrutura agrária, fronteira agrícola e trabalhadores rurais no Brasil. Rio de Janeiro: Zahar, 1982.

GRAZIANO DA SILVA, José. Do complexo rural aos complexos agroindustriais. In:GRAZIANO DA SILVA, José. A nova dinâmica da agricultura brasileira. Campinas: Unicamp/IE, 1996. p. 1-40.

GUTIÉRREZ, Gustavo. Teologia da Libertação. 2. ed. Petrópolis: Vozes, 1976.

GUTIÉRREZ, Gustavo. A força histórica dos pobres. Petrópolis: Vozes, 1981.

HABERMAS, Jürguen. Consciência moral e agir comunicativo. Rio de Janeiro: Tempo Brasileiro, 1989.

HABERMAS, Jürguen. Para a reconstrução do materialismo histórico. 2. ed. São Paulo: Brasiliense, 1990. 
MACHADO, Ilma Ferreira. A organização do trabalho pedagógico em uma escola do MST e a perspectiva de formação omnilateral. 2003. $325 \mathrm{f}$. Tese (Doutorado em Educação) - Programa de Pós-Graduação em Educação, Universidade Estadual de Campinas, Campinas, 2003.

MATOS, Patrícia Francisca; PESSOA, Vera Lúcia Salazar. A modernização da agricultura no Brasil e os novos usos do território. Geo UERJ, Rio de Janeiro, ano 13, v. 2, n. 22, p. 290-322, 2011. Disponível em: <http://www.e-publicacoes.uerj.br/index.php/geouerj/article/view/2456>. Acesso em: 29 maio 2016.

ORO, Ivo Pedro. Militantes x igreja: tensões e perspectivas. Chapecó: Unoesc, 1992.

MOVIMENTO DE MULHERES CAMPONESAS DE SANTA CATARINA. Uma história de organização, lutas e conquistas. Chapecó: ROTA, 2008. [Cartilha].

PACHECO, Maria Emília. Entrevista sobre agroecologia. 2002. Disponível em: <http://www.historianet.com. br>. Acesso em: 29 maio 2016.

PICOLOTTO, Everton Lazaretti. Processos de diferenciação dos movimentos sociais do campo no Sul do Brasil: identidade, articulação política e projeto. Raízes, Campina Grande, v. 26, n. 1-2, p. 46-58, jan./dez. 2007. Disponível em: <http://www.ufcg.edu.br/ raizes/artigos/Artigo_188.pdf>. Acesso em: 29 jun. 2016.

POLI, Odilon Luiz. Aprendendo a andar com as próprias pernas: processo de mobilização nos movimentos sociais do Oeste Catarinense. 1995. Dissertação (Mestrado em Educação) - Programa de Pós-Graduação em Educação, Universidade Estadual de Campinas, Campinas, 1995.

POLI, Odilon Luiz. Cultura e modo de vida camponês no Oeste Catarinense: as bases para a organização frente à crise dos anos 70. Cadernos do CEOM, Chapecó, ano 16, n. 15, p. 72-102, jun. 2002.

POLI, Odilon Luiz. Leituras em Movimentos Sociais. 2. ed. Chapecó: Argos, 2008.

SCHERER-WARREN, Ilse. Movimentos Sociais: um ensaio de interpretação sociológica. 3. ed. Florianópolis: Editora da UFSC, 1989.

SCHERER-WARREN, Ilse. Redes de movimentos sociais. São Paulo: Loyola, 1993.

SCHERER-WARREN, Ilse. Redes de movimentos sociais na América Latina: caminhos para uma política 
emancipatória? Cad. CRH, Salvador, v. 21, n. 54, p. 505-517, dez. 2008. Disponível em: <http://www. scielo.br/scielo.php? script $=$ sci_arttext\&pid $=$ So103$-49792008000300007 \& \operatorname{lng}=\mathrm{en} \& \mathrm{nrm}=\mathrm{iso}>$. Acesso em: 21 jun. 2016.

SCHERER-WARREN, Ilse; KRISCHKE, Paulo (Org.). Uma revolução no cotidiano: novos movimentos sociais na América Latina. São Paulo: Brasiliense, 1987.

SILVA, Samuel Ramos da. Movimento, comunicação e linguagem na educação de jovens e adultos do MST.2003. 167 f. Dissertação (Mestrado em Educação) Programa de Pós-Graduação em Educação, Universidade Federal de Santa Catarina, Florianópolis, 2003.

STEDILE, João Pedro; CARVALHO, Horacio Martins de. Soberania Alimentar: uma necessidade dos povos. Revista Cidadania e Meio Ambiente, Rio de Janeiro, v. 25, 2011.

STRAPAZZON, João Paulo Lajus. E o verbo se fez terra: Movimento dos Trabalhadores Rurais sem Terra (SC) 1980-1990. Chapecó: Grifos, 1998.

TARELHO, Luiz Carlos. Os Sem Terra de Sumaré: da consciência dos direitos à identidade social. 1988. oo f. Dissertação (Mestrado em Psicologia Social) - Programa de Pós-Graduação em Psicologia Social, Pontifícia Universidade Católica de São Paulo, São Paulo, 1988. Mimeo.

THOMPSON, Edward Paul. A formação da classe operária inglesa. 1. ed. Rio de Janeiro: Paz e Terra, 1987.

THOMPSON, Edward Paul. A miséria da teoria ou um planetário de erros. Rio de Janeiro: Zahar, 1981.

UCZAI, Pedro Francisco (Org.). Dom José Gomes: mestre e aprendiz do povo.Chapecó: Argos, 2002.

VENDRAMINI, Célia Regina. Experiência e coletividade em E. P. Thompson. In: MÜLLER, Ricardo Gaspar; DUARTE, Adriano Luiz (Org.). E. P. Thompson: política e paixão. Chapecó: Argos, 2012. p. ?

WERLANG, Alceu Antônio. A colonização do Oeste Catarinense. Chapeco: Argos, 2002.

WOORTMANN, Klaas. Com parente não se neguceia: o campesinato como ordem moral. Anuário Antropológico/87, Brasília, p. 11-73, 1990. 